\title{
Microincisional vitrectomy for retinal detachment in I- 125 brachytherapy-treated patients with posterior uveal malignant melanoma
}

This article was published in the following Dove Press journal:

Clinical Ophthalmology

26 February 2013

Number of times this article has been viewed

\author{
Marcela Lonngi' \\ Samuel K Houston' \\ Timothy G Murray ${ }^{1-3}$ \\ Robert A Sisk ${ }^{4}$ \\ Christina L Decatur ${ }^{\prime}$ \\ Milena Cavalcante' \\ Arnold M Markoe ${ }^{3}$ \\ 'Department of Ophthalmology, \\ Bascom Palmer Eye Institute, \\ University of Miami, Miller School \\ of Medicine, Miami, FL, USA; ${ }^{2}$ Murray \\ Ocular Oncology and Retina, Miami, \\ FL, USA; ${ }^{3}$ Department of Radiation \\ Oncology, University of Miami Miller \\ School of Medicine, Miami, FL, USA; \\ ${ }^{4}$ Department of Ophthalmology, \\ Cincinnati Eye Institute, Cincinnati, \\ $\mathrm{OH}$, USA
}

Purpose: To analyze functional and anatomical outcomes following $23 / 25^{+}$gauge microincisional pars plana vitrectomy surgery (MIVS) in patients with radiation-related retinal detachment after successful 125-iodine (I-125) brachytherapy treatment for malignant uveal melanoma.

Patients and methods: Retrospective case series of 102 consecutive eyes of 102 patients with history of uveal melanoma treated with I-125 brachytherapy that underwent MIVS at the Bascom Palmer Eye Institute. All cases were evaluated for surgical complications and local tumor control. Extended follow-up included Snellen's best-corrected visual acuity, intraocular pressure evaluation, quantitative echography, indirect ophthalmoscopy, and fundus imaging with optical coherence tomography/wide-field photography.

Results: All patients had radiation-related complications, including retinal detachment (102 eyes), vasculopathy (91 eyes), optic neuropathy (32 eyes), and/or vitreous hemorrhage ( 8 eyes). Sixty-seven patients had vitreoretinal traction. Average follow-up after MIVS was 19.5 months, and from plaque removal was 57.7 months. Interval from plaque to MIVS was 38.1 months. Initial visual acuity was 20/258, which improved to 20/101 at 1 month, 20/110 at 3 months, 20/116 at 6 months, and 20/113 at 12 months $(P<0.05)$. No eyes required enucleation. Melanoma-related mortality was $0.9 \%(1 / 102)$. There was no intra- or extraocular tumor dissemination, and no tumor recurrence.

Conclusion: MIVS was effective in improving visual function and anatomy in patients with radiation-related retinal detachment. Tumors decreased in size and there was no evidence of recurrence or tumor dissemination. This combined procedure addresses the modifiable causes of visual loss in patients with previously treated malignant uveal melanoma and has the potential to enhance their visual function.

Keywords: retinal detachment, vitrectomy, melanoma, radiation-related complications

\section{Introduction}

Uveal melanoma (UM) is the most common intraocular malignancy in adults, with an incidence of 5-6 cases per million per year. ${ }^{1,2}$ The incidence rate in nonwhites is extremely low; in the United States, it is less than one-eighth of the rate for whites. ${ }^{2}$ It is usually diagnosed in the sixth decade of life, with a slight predominance of males. ${ }^{2}$ Among all melanoma cases reported in the United States, approximately 5\% arise from the ocular and adnexal structures; of these, $85 \%$ correspond to $\mathrm{UM}^{3}{ }^{3}$ It is the most common noncutaneous form of melanoma. ${ }^{1,2}$ Most patients with UM have no known family history of the disease, even though there are a few reports of sporadic familiar cases. $^{2}$ Although heredity may not play a role in most cases, cytogenetic analyses of UM tissue have revealed that alterations in chromosomes 3 and 8 may be associated with increased metastasis-related mortality. ${ }^{2}$
Correspondence: Timothy G Murray Murray Ocular Oncology \& Retina, 6705 Red Road, Suite 412, South Miami, FL 33143, USA

Tel +I 3054877470

Fax +l 7865674380

Email tmurray@med.miami.edu 
The Collaborative Ocular Melanoma Study found that eyes treated with 125-iodine (I-125) brachytherapy compared to enucleation had no difference in mortality (43\% and $41 \%$, respectively), or in the development of metastasis (21\% and $17 \%$, respectively) at 12 years of follow-up. ${ }^{3}$ Consequences of radiation on the sensitive ocular structures involves apoptosis, cell migration, clotting cascades, increased vascular endothelial permeability, aneurysm formation, telangiectasia, and neovascularization. ${ }^{3,4}$ As a result, radiation-related complications include retinal detachment, cataract formation, radiation optic neuropathy, severe visual loss, neovascular glaucoma, nerve-fiber layer infarcts, retinal hemorrhages, and vitreous hemorrhage. ${ }^{3,4}$

Posterior UM is commonly associated with retinal detachment., ${ }^{5,6}$ Exudative retinal detachments have an incidence of $50 \%$ to $100 \%$ prior to treatment. ${ }^{7}$ They tend to improve after treatment with brachytherapy, but may recur. Furthermore, secondary vitreous fibrosis and epiretinal membranes add a tractional component along the peripheral edges of treated tumors. Observation of chronic detachments leads to irreversible visual loss due to photoreceptor damage. ${ }^{5,6}$ Different approaches have been proposed, including surgical drainage, endolaser, cryotherapy, and antivascular endothelial growth factor. ${ }^{6}$

The aim of this study is to describe the microincisional surgical management of retinal detachment secondary to radiation-related complications, and to determine safety, visual function, and anatomic outcomes of eyes previously treated with I-125 brachytherapy for UM.

\section{Material and methods}

\section{Patients}

After obtaining approval by the University of Miami Institutional Review Board, we reviewed the charts of 102 patients with history of malignant UM previously treated with I-125 brachytherapy within the Ocular Oncology Service at the Bascom Palmer Eye Institute that underwent 23/25+ gauge microincisional pars plana vitrectomy (MIVS) between March 2005 and July 2011 by an ocular oncologist (TGM) and his vitreoretinal surgical fellows. Inclusion criteria included the presence of radiation-related retinal detachment, and minimum follow-up of 6 months after vitrectomy. Indications for surgery included retinal detachment, radiation retinopathy, and visually significant cataract.

Recorded data included patient age, sex, involved eye, systemic disease, dates of plaque therapy, pars plana vitrectomy (PPV), tumor location, best-corrected visual acuity (BCVA), and tumor dimensions. Additional information included intraocular pressure (IOP), ocular comorbidity, radiation complications at the time of the PPV, PPV complications, systemic complications after PPV, presence of malignancy on vitreous cytology, intra- and extraocular metastasis, and need for further surgery. Data were recorded at 1 week, at 1, 3, 6, and 12 months, and at $2,3,4$, and 5 years.

\section{Surgical procedure}

After informed consent was obtained, patients received local or general anesthesia. Betadine preparation and sterile draping was performed, and the $23 / 25^{+}$gauge trochars were inserted in a beveled fashion $3.5 \mathrm{~mm}$ posterior to the limbus, then directed perpendicularly towards the optic nerve. The infusion cannula was secured into place, confirmed to be in the correct intraocular location by direct visualization, and turned on. The posterior hyaloid was removed, and vitrectomy was performed using the A.V.I. 130 wide-field viewing system (Advanced Visual Instruments, New York, NY, USA). In some patients, vitrectomy was combined with other procedures, including phacoemulsification and intraocular lens (IOL) insertion, air-fluid exchange, release of vitreoretinal traction, membrane peel, epiretinal membrane/internal limiting membrane removal, laser tumor ablation, sectoral panretinal photocoagulation, retinotomy, use of internal tamponade with $\mathrm{C}_{3} \mathrm{~F}_{8}$ gas or silicone oil, synechiolysis, and conjunctival cyst or lid lesions removal. The vitreous cassette was sent to evaluate for vitreous seeding. All vitreous samples were cytospun, filtered, and the filter was stained. These cells were then evaluated by a highly experienced ocular pathologist for evidence of viable melanoma cells. Intravitreal triamcinolone acetonide $4 \mathrm{mg} / 0.1 \mathrm{~mL}$ (Triesence ${ }^{\circledR}$, Alcon, Fort Worth, TX, USA) or bevacizumab $2.5 \mathrm{mg} / 0.1 \mathrm{~mL}$ (Avastin $^{\circledR}$, Genentech, San Francisco, CA, USA) was injected into any eye not receiving tamponade following removal of the last cannula. Gentamicin $20 \mathrm{mg}$ and dexamethasone $4 \mathrm{mg}$ were administered away from the sclerotomies in the inferior subconjunctival space at the conclusion of the procedure in all eyes. Patients were observed after radioactive plaque treatment with serial fundoscopic examinations and ultrasonography to confirm tumor control before proceeding for surgery for visual rehabilitation. Postoperatively, patients were evaluated at 1 day, at 1 week, at 1,3,6, and 12 months, and then every 6 weeks to 6 months according to their condition.

\section{Analysis}

Snellen's BCVA was converted to logMAR acuities for data analysis. Acuities unable to be assessed with Snellen charts 
were converted using the following convention: count fingers (CF) 20/2000; hand motions (HM) 20/20,000; and light perception (LP) 20/200,000. LogMAR acuities were compared with baseline values using the paired $t$ test to preoperative versus postoperative differences. A $P$ value $\leq 0.05$ was considered statistically significant.

\section{Results}

A total of 102 eyes (50 right eyes and 52 left eyes) of 102 patients were evaluated. Sixty-three patients were female $(63 / 102,61.7 \%)$ and thirty-nine patients were male $(39 / 102,38.2 \%)$. The mean patient age at surgery was 67 years (range $41-102$ years). Associated systemic disease comorbidities are presented in Table 1. Average follow-up after vitrectomy was 19.5 months (range 6.1-54.6), and total follow-up from plaque removal to last follow-up appointment was 57.7 months (range 12.0-219.9). Average time from plaque to PPV was 38.1 months (range 3.8-178.6). Fifty-nine patients $(57.8 \%)$ had a choroidal melanoma, 37 patients $(36.2 \%)$ had ciliochoroidal detachment, and six patients $(5.8 \%)$ had a ciliary body tumor with posterior/ anterior extension. All patients had radiation-related complications, including retinal detachment at the time of surgery in all eyes (100\%), vasculopathy in 91 eyes $(89.2 \%)$, optic neuropathy in 32 eyes (31.3\%), and vitreous hemorrhage in eight eyes $(7.8 \%)$ (Table 1$)$.

\section{Visual acuity outcomes}

The mean baseline BCVA in the affected eye was 20/258. At 1-week follow-up, BCVA improved to 20/157, at 1 month to $20 / 101$, at 3 months to $20 / 110$, at 6 months to $20 / 116$, and at 12 months to 20/113. Improvements in visual acuity (VA) were statistically significant from baseline to all follow-up intervals $(P<0.05)$ (Figure 1$)$.

At 3 months, 37.6\% gained two or more lines of vision compared with baseline while $8.6 \%$ lost two or more lines (Figure 2). At 6 months, 32.5\% gained two or more lines of vision compared with baseline while $8.9 \%$ lost two or more lines (Figure 3). At 12 months, 36.7\% gained two or more lines of vision compared with baseline while 19.1\% lost two or more lines (Figure 4).

Final BCVA was better than 20/50 in 37 patients $(36.2 \%)$, between $20 / 50$ and $20 / 400$ in 36 patients $(35.2 \%)$, and between $20 / 400$ and $5 / 200$ in 19 patients (18.6\%). Only 10 patients $(9.8 \%)$ had a nonambulatory final VA (worse than 5/200) (Table 2). From the group of patients with final $\mathrm{VA} \geq 20 / 50$ (37/102), 37.8\% (14/37) had a final BCVA of $20 / 25,21.6 \%(8 / 37)$ of $20 / 40,13.5 \%(5 / 37)$ of $20 / 20,13.5 \%$
$(5 / 37)$ of $20 / 30$, and $13.5 \%$ (5/37) of 20/50 (Figure 5). The mean BCVA prior to surgery for this group of patients was $20 / 73$, with a statistically significant improvement after the surgical procedure $(P<0.05)$ (Table 2$)$.

\section{Clinical findings}

The current study did not find an increased incidence of complications related to the vitrectomy. There were no cases of endophthalmitis or suprachoroidal hemorrhage. Vitreous biopsy was positive in three patients. Six patients developed systemic metastasis $(5.8 \%)$. Retinal toxicity from intravitreal or subconjunctival injections was not observed. Nine patients $(8.8 \%)$ developed secondary neovascular glaucoma. No eyes required enucleation, but one patient died from metastatic disease $(0.9 \%)$. Mean IOP did not present a statistically significant increase after the procedure (13 $\mathrm{mmHg}$ at baseline and $14 \mathrm{mmHg}$ at the last follow-up; $P>0.05)$ (Table 1).

\section{Anatomic outcomes}

There was no intra- or extraocular tumor dissemination, and no cases of tumor recurrence. Average tumor size (length $\times$ width $\times$ height) showed a statistically significant decrease after I-125 plaque brachytherapy treatment $(13.83 \times 11.43 \times 4.23 \mathrm{~mm}$ before brachytherapy versus $11.50 \times 10.09 \times 2.66 \mathrm{~mm}$ after brachytherapy), and, again, after MIVS $(10.70 \times 9.36 \times 1.96 \mathrm{~mm})$, with a $P$ value $<0.05$ (Figure 6). Seven patients required surgical reintervention $(6.86 \%)$, and three patients had persistence of exudative retinal detachment at the last follow-up (2.94\%).

\section{Case report}

A 59 year-old male with history of posterior UM in the left eye, macula located, measuring $12 \times 8.5 \times 2.6 \mathrm{~mm}$, was treated with I-125 brachytherapy in August 2004. He presented for follow-up appointment 88 months after treatment with a decrease in VA in the left eye. He had history of hypertension and hypercholesterolemia. On ocular examination, BCVA was 20/25 OD and 20/60 OS, IOP 12 and 14, the iris was flat, without rubeosis or mass. He presented with a $2+$ nuclear cataract in the left eye. Comprehensive ophthalmoscopy showed a small nevus in the right eye with no malignant transformation or vascular activity. Evaluation of the left eye showed a small cup-to-disc ratio, good rim coloration and perfusion, increasing vascular activity with radiation retinopathy, and a dome-shaped lesion with involution to a size of $9 \times 8.5 \times 1 \mathrm{~mm}$, with focal exudative retinal detachment just superior to macula (Figure 7A). 
Table I Patient demographics and characteristics ( $\mathrm{n}=102$ eyes)

\begin{tabular}{|c|c|c|}
\hline Mean age & 67 years (range $4 I-102$ years) & \\
\hline Sex & Male $38.23 \%(n=39)$ & Female $61.76 \%(n=63)$ \\
\hline Eye & Right $49.01 \%(n=50)$ & Left $50.98 \%(n=52)$ \\
\hline \multirow[t]{7}{*}{ Systemic disease } & Hypertension & $51.96 \%(n=53)$ \\
\hline & Hypercholesterolemia & $24.50 \%(n=26)$ \\
\hline & Nonocular malignancy & $19.60 \%(n=20)$ \\
\hline & Diabetes mellitus & $11.76 \%(n=12)$ \\
\hline & Thyroid disease & $9.80 \%(n=10)$ \\
\hline & Other & $57.84 \%(n=59)$ \\
\hline & None & $15.68 \%(n=16)$ \\
\hline \multirow[t]{7}{*}{ Comorbidity } & Hypertensive retinopathy & $47.06 \%(n=48)$ \\
\hline & Age-related macular degeneration & $16.67 \%(n=17)$ \\
\hline & Glaucoma & $15.69 \%(n=16)$ \\
\hline & Epiretinal membrane & $9.80 \%(n=10)$ \\
\hline & Diabetic retinopathy & $3.92 \%(n=4)$ \\
\hline & Other & $28.43 \%(n=29)$ \\
\hline & None & $7.14 \%(n=7)$ \\
\hline \multirow[t]{3}{*}{ Tumor location } & Choroidal & $57.84 \%(n=59)$ \\
\hline & Ciliochoroidal & $36.27 \%(n=37)$ \\
\hline & Ciliary body & $5.88 \%(n=6)$ \\
\hline Average time plaque-PPV & 38.I months (range 3.8-178.6 months) & \\
\hline \multirow[t]{5}{*}{ Radiation-related complications (pre-PPV) } & Vasculopathy & $89.22 \%(n=91)$ \\
\hline & Optic neuropathy & $31.37 \%(n=32)$ \\
\hline & Vitreous hemorrhage & $7.84 \%(n=8)$ \\
\hline & Other & $0.98 \%(n=I)$ \\
\hline & None & $0 \%(n=0)$ \\
\hline Average follow-up from PPV & I9.5 months (range 6.I-54.6 months) & \\
\hline Average follow-up from plaque & 57.7 months (range 12.0-219.9 months) & \\
\hline Positive vitreous biopsy & $2.94 \%(n=3 / 76)$ & \\
\hline Metastasis & $5.88 \%(n=6)$ & \\
\hline \multirow[t]{8}{*}{ Clinical findings } & Secondary glaucoma & $8.82 \%(n=9)$ \\
\hline & Surgical re-intervention & $6.86 \%(n=7)$ \\
\hline & Persistence of retinal detachment & $2.94 \%(n=3)$ \\
\hline & Mortality & $0.98 \%(n=I)$ \\
\hline & Intraocular tumor dissemination & $0 \%(\mathrm{n}=0)$ \\
\hline & Extraocular tumor dissemination & $0 \%(n=0)$ \\
\hline & Tumor recurrence & $0 \%(n=0)$ \\
\hline & Enucleation & $0 \%(n=0)$ \\
\hline \multirow[t]{3}{*}{ Mean IOP } & Initial & 13.98 \\
\hline & Last follow-up & 14.06 \\
\hline & $P$ value & 0.45 \\
\hline
\end{tabular}

Abbreviations: IOP, intraocular pressure; PPV, pars plana vitrectomy.

After the risks, benefits and alternatives were discussed, informed consent was obtained and the patient underwent 23G MIVS combined with phacoemulsification, IOL implantation, membrane peeling, endolaser tumor ablation, vitreous biopsy, and intravitreal triamcinolone acetonide injection to the left eye (Figure 8). At 1 month, postoperative VA improved to 20/50 with improvement, but persistence of vascular activity secondary to radiation maculopathy. IOP was 14. The tumor was stable, and the retina was attached with no proliferative vitreoretinopathy formation. Vitreous biopsy result was negative for malignancy.
Bevacizumab $1.25 \mathrm{mg} / 0.05 \mathrm{~mL}$ was injected OS. At 3 months follow-up, BCVA improved to 20/25, IOP was 13 , and the primary tumor was stable, with laser ablation and intratumoral focal hemorrhage (Figure 7B).

\section{Discussion}

Retinal detachment is a common complication in patients with a history of posterior uveal melanoma (UM), which may lead to permanent photoreceptor damage and visual loss. ${ }^{5,7}$ Detachments can be either exudative, tractional, rhegmatogenous, or combined. Initially, retinal detachment is related 


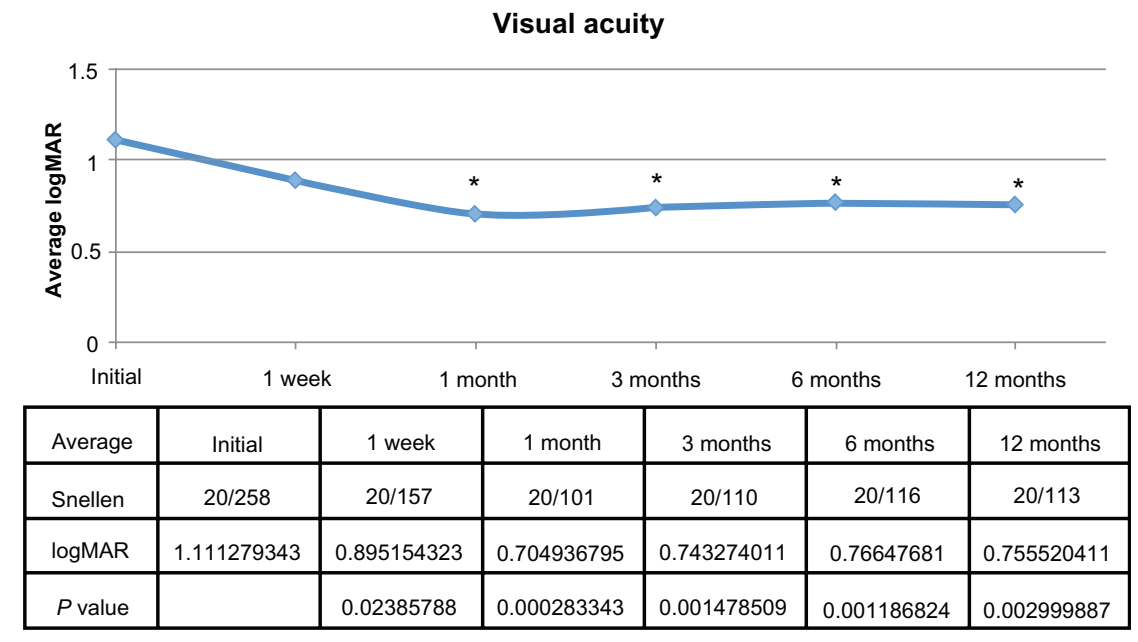

Figure I Logarithm of the minimum angle of resolution (logMAR) mean visual acuity before pars plana vitrectomy (initial), at I week, and at I, 3, 6, and I2 months after surgery.

Note: *There was a statistically significant improvement in visual acuity after the procedure $(P<0.05)$.

Visual acuity at 3 months

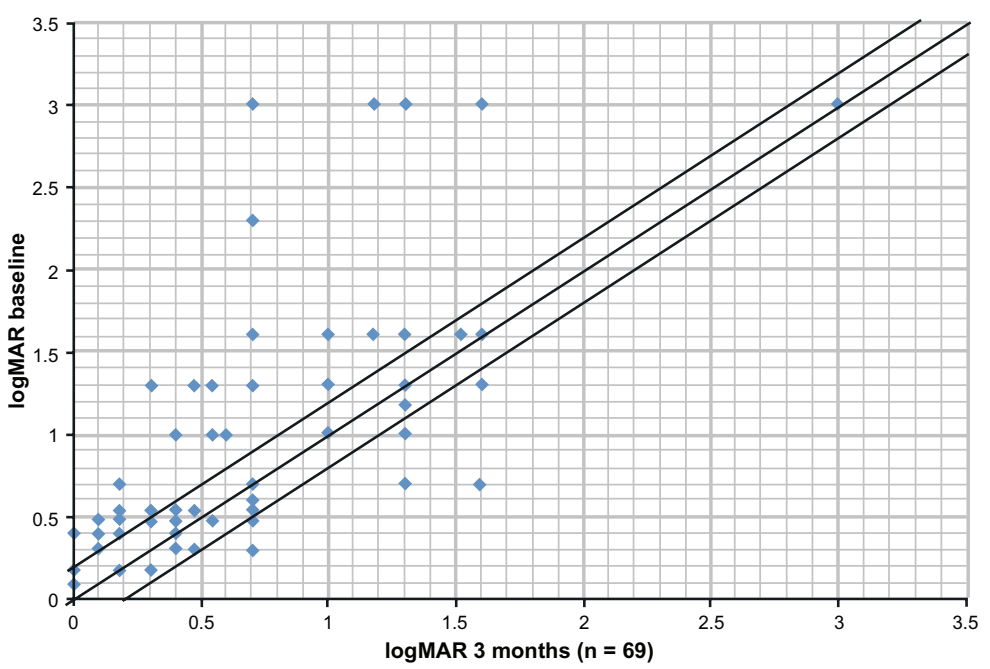

Figure 2 Scatter plot of pre- versus postoperative logarithm of the minimum angle of resoluction (logMAR) visual acuities at 3 months.

Visual acuity at 6 months

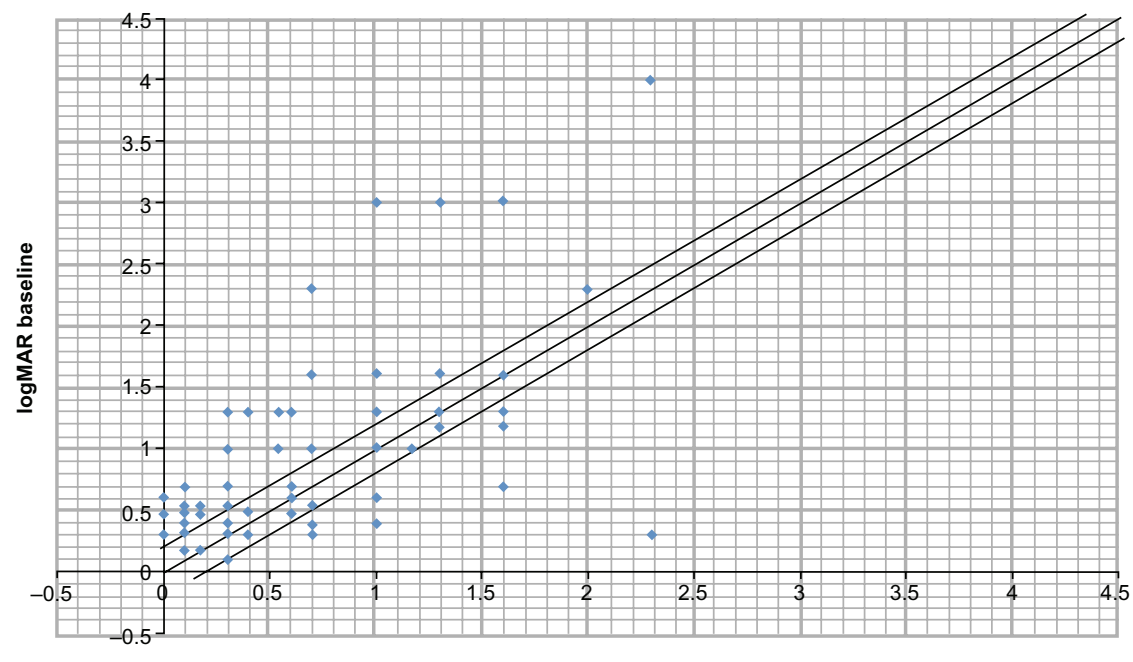

$\log M A R 6$ months $(n=89)$

Figure 3 Scatter plot of pre- versus postoperative logarithm of the minimum angle of resoluction (logMAR) visual acuities at 6 months. 


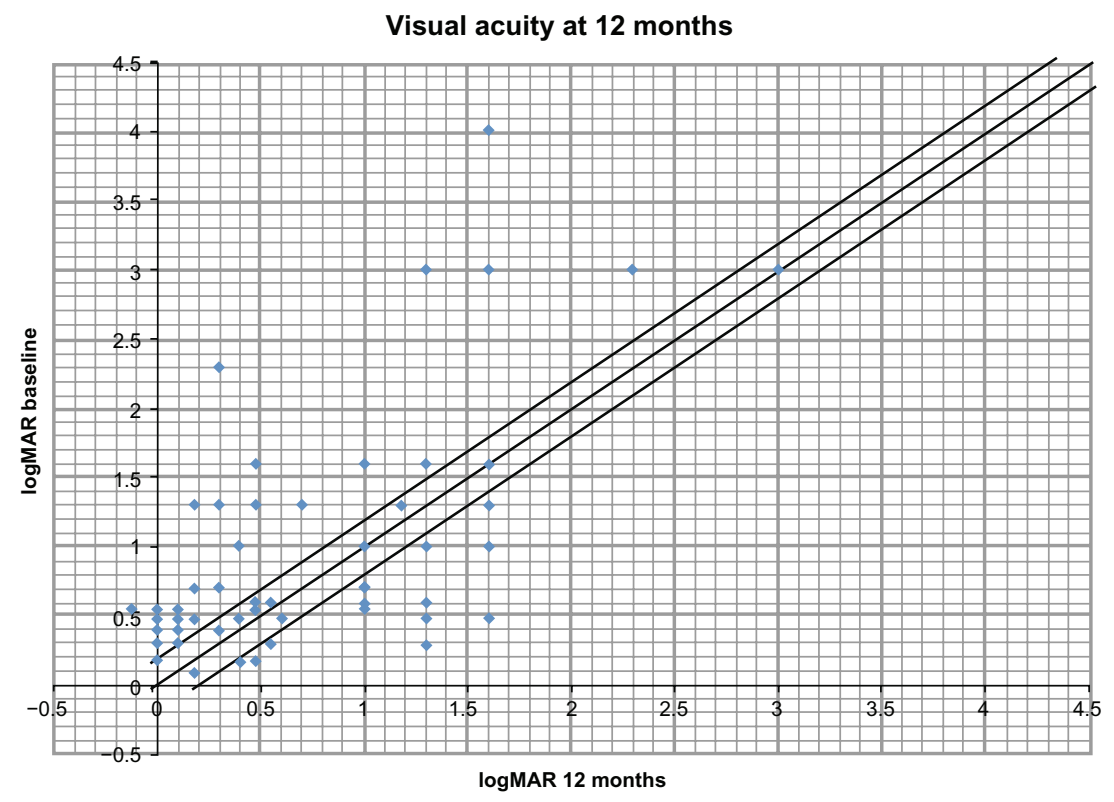

Figure 4 Scatter plot of pre- versus postoperative logarithm of the minimum angle of resoluction (logMAR) visual acuities at I2 months.

to intrinsic tumor vascular activity, but after brachytherapy treatment, it can be a consequence of radiation vasculopathy. ${ }^{5}$ In addition, following plaque brachytherapy, we have observed significant vitreoretinal interface changes along the peripheral tumor edges. With these vitreoretinal adhesions causing tractional changes, tractional or rhegmatogenous detachments may result. When fluid poses a threat to the macula, retinal detachment management may prevent longterm visual loss. ${ }^{7}$

Vitrectomy has undergone continuous advancements in instrumentation, design, and utility. ${ }^{7}$ Indications for patients with a history of treated UM vary from tumor-related complications, such as exudative detachments, to radiationrelated complications including radiation retinopathy, vitreous hemorrhage, tractional, and rhegmatogenous retinal detachments. ${ }^{7}$ Before proceeding with surgery, observation is essential in order to rule out tumor activity, which is determined by a decrease in the tumor vascularity, volume, and exudative retinal detachment. Some ocular oncologists suggest at least 6 months of observation following tumor treatment to ensure tumor stability. ${ }^{7}$

Several studies have established the safety of PPV in eyes containing a treated melanoma. Foster et $\mathrm{al}^{8}$ conducted

Table 2 Visual acuity

\begin{tabular}{ll}
\hline$\geq 20 / 50$ & $36.27 \%(n=37)$ \\
$20 / 50-20 / 400$ & $35.29 \%(n=36)$ \\
$20 / 400-5 / 200$ & $18.62 \%(n=19)$ \\
$<5 / 200$ & $9.80 \%(n=10)$ \\
\hline
\end{tabular}

a retrospective study of nine patients treated with I-125 brachytherapy or transpupillary thermotherapy. One patient with vitreous hemorrhage established before tumor treatment, developed intraocular tumor dissemination 56 months after vitrectomy. He had melanoma cells in the vitreous aspirate. In our series, eight of 102 patients had vitreous hemorrhage that presented after radiation therapy. One of them had a positive vitreous biopsy, and none developed intra- or extraocular tumor dissemination.

One of our previous studies ${ }^{9}$ retrospectively evaluated 114 eyes of 111 patients who underwent combined phacoemulsification and 23-gauge vitrectomy for retinal pathology; 31 eyes had primary malignant UM. Patients were observed for a minimum of 6 months with serial exams documenting tumor stability. Following PPV, adverse effects such as intraocular tumor dissemination, endophthalmitis, and hypotony have been described., ${ }^{5-15}$ In the current study, there were no cases of intra- or extraocular dissemination, tumor recurrence, endophthalmitis, or suprachoroidal hemorrhage.

An interventional study by Gibran and Kapoor ${ }^{5}$ evaluated six patients with exudative retinal detachment associated with UM. Treatment included proton-beam radiation or brachytherapy, tumor biopsy, and surgical treatment of exudative retinal detachment, including vitrectomy and drainage of subretinal fluid at the time of irradiation. The patients had significant restoration of vision, regression of tumor thickness, no extrascleral extension or metastasis, and no recurrence of exudative retinal detachment. 


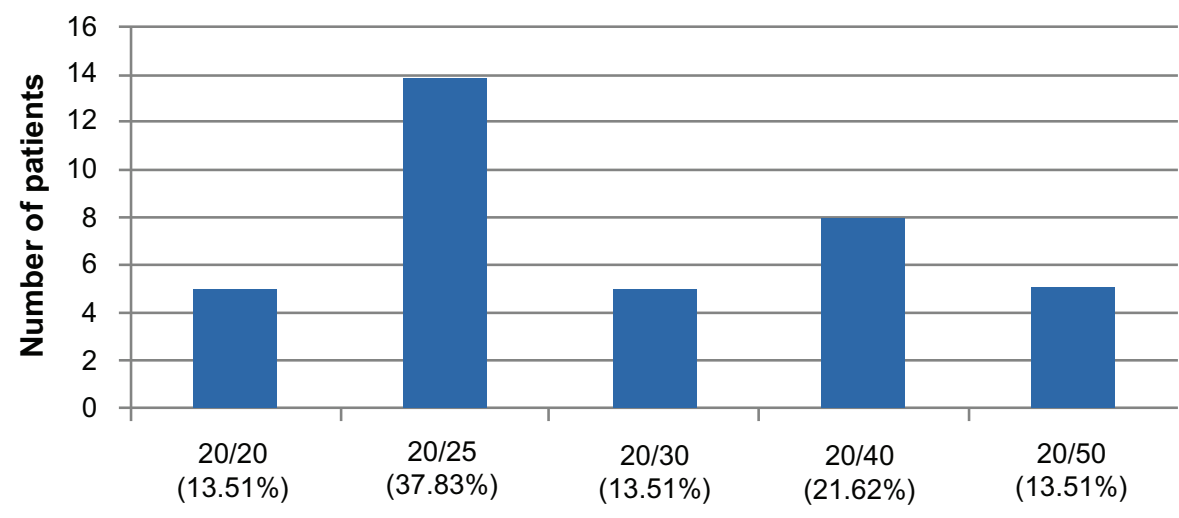

Snellen visual acuity

Figure 5 Final best-corrected visual acuity in patients with visual acuity $\geq 20 / 50$ group $(n=37 / / 02)$.

\section{Tumor size}

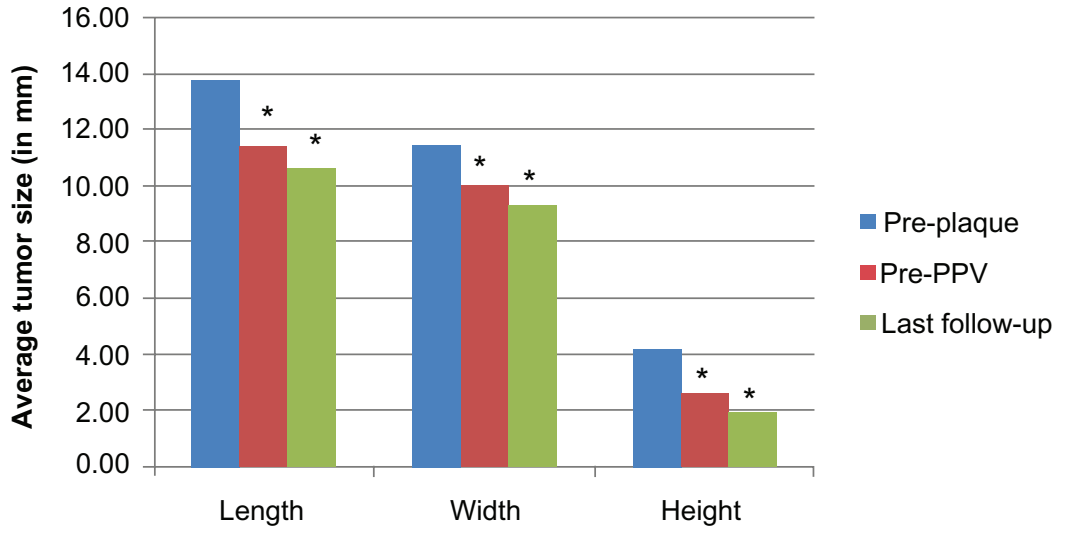

\begin{tabular}{|c|c|c|c|}
\hline \multicolumn{4}{|c|}{ Average tumor size in mm } \\
\hline & Length & Width & Height \\
\hline Pre-plaque & 13.83 & 11.43 & 4.23 \\
\hline Pre-PPV & 11.50 & 10.09 & 2.66 \\
\hline Last follow-up & 10.70 & 9.36 & 1.96 \\
\hline
\end{tabular}

Figure 6 Average tumor size $(P<0.05)$.

Note: *statistically significant, $P<0.05$.

Abbreviation: PPV, pars plana vitrectomy.

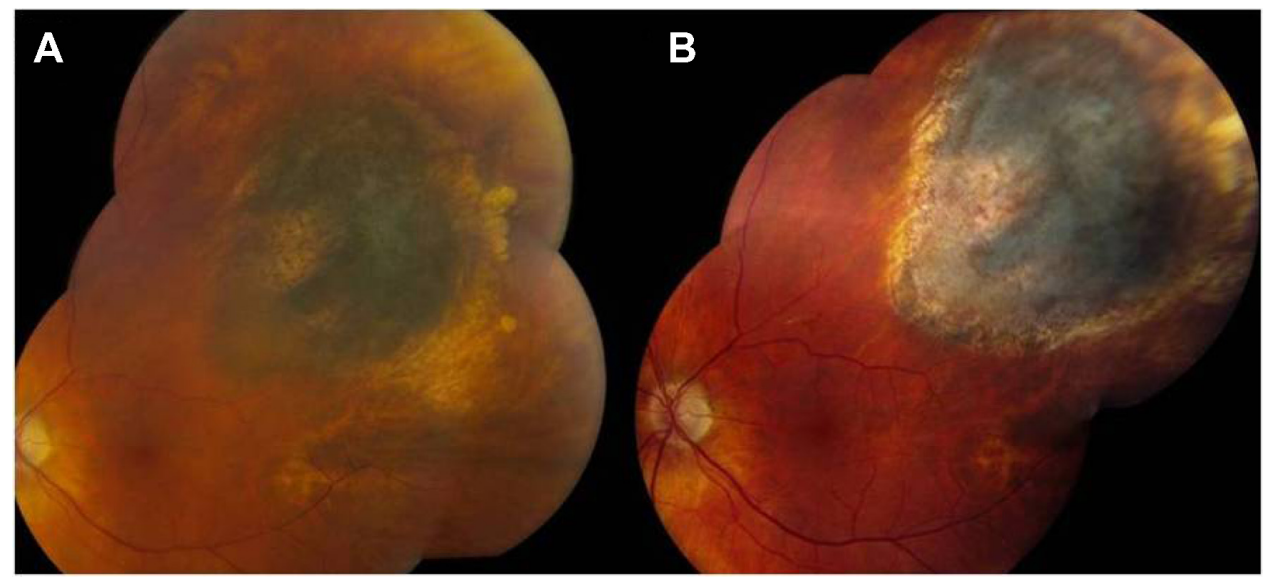

Figure 7 (A) Preoperative fundus photograph. (B) Three months postoperative fundus photograph. 


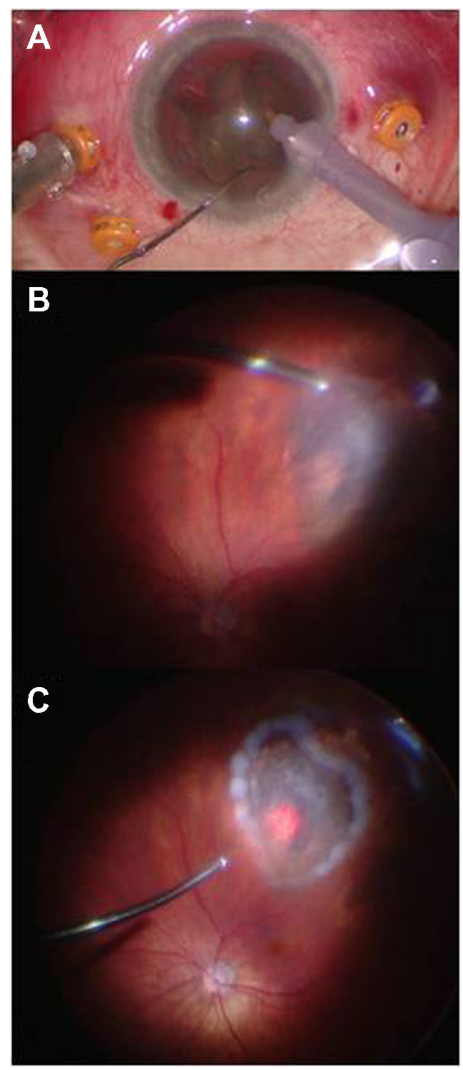

Figure 8 Combined microincisional vitrectomy and phacoemulsification. (A) Phacomulsification with intraocular lens implantation. (B) 23-gauge pars plana vitrectomy, and membrane peel. (C) Laser tumor ablation.

Exudative retinal detachments prior to radiation treatment are present in $50 \%$ to $100 \%$ of the cases. ${ }^{7,12,15-18}$ They tend to improve over time, with a mean of 5.6 months and $90 \%$ resolution at 1 year. ${ }^{7,19-21}$ Even though early management of exudative retinal detachment may prevent photoreceptor damage, we consider that tumors should be inactive before proceeding with intraocular surgery to avoid tumor dissemination. Additionally, in the present study we obtained a statistically significant improvement of VA after microincisional vitrectomy, indicating that visual function can be enhanced in these patients.

\section{Conclusion}

Microincisional pars plana vitrectomy was safe and effective in improving visual function and anatomy in patients with complex radiation-related retinal detachment after I-125 brachytherapy treatment for UM. Tumors decreased in size and there was no evidence of tumor dissemination or recurrence. Direct endolaser tumor ablation, and intravitreal triamcinolone acetonide or bevacizumab injection at the time of surgery may reduce rates of ongoing radiation-related complications including radiation vasculopathy.
This procedure approach addresses the modifiable causes of visual loss in patients with previously treated malignant UM and has the potential to improve visual function for this complex patient series.

\section{Disclosure}

The authors report no conflicts of interest in this work.

\section{References}

1. Singh AD, Turell ME, Topham AK. Uveal melanoma: trends in incidence, treatment, and survival. Ophthalmology. 2011;118:1881-1885.

2. Ryan SJ. Choroidal melanoma and related issues. In: Ryan SJ, editor. Retina. 4th ed. Philadelphia, PA: Elsevier; 2006.

3. Collaborative Ocular Melanoma Study Group. The COMS randomized trial of iodine 125 brachytherapy for choroidal melanoma. V. Twelveyear mortality rates and prognostic factors: COMS report no 28. Arch Ophthalmol. 2006;124:1684-1693.

4. Jampol LM, Moy CS, Murray TG, et al. The COMS randomized trial of iodine 125 brachytherapy for choroidal melanoma: IV. Local treatment failure and enucleation in the first 5 years after brachytherapy. COMS report no 19. Ophthalmology. 2002;109:2197-2206.

5. Gibran SK, Kapoor KG. Management of exudative retinal detachment in choroidal melanoma. Clin Experiment Ophthalmol. 2009;37: 654-659.

6. Newman H, Finger P, Chin KJ, Pavlick AC. Systemic bevacizumab (Avastin) for exudative retinal detachment secondary to choroidal melanoma. Eur J Ophthalmol. 2011;21:796-801.

7. Houston SK. Lonngi M, Markoe A, Murray TG. When to consider vitrectomy in eyes with posterior uveal melanoma. Retinal Physician. 2012;9:24-28

8. Foster WJ, Harbour JW, Holekamp NM, Shah GK, Thomas MA. Pars plana vitrectomy in eyes containing a treated posterior uveal melanoma. Am J Ophthalmol. 2003;136:471-476.

9. Sisk RA, Murray TG. Combined phacoemulsification and sutureless 23-gauge pars plana vitrectomy for complex vitreoretinal diseases. $\mathrm{Br}$ J Ophthalmol. 2010;94:1028-1032.

10. Harbour JW, Ahmad S, El-Bash M. Rate of resolution of exudative retinal detachment after plaque radiotherapy for uveal melanoma. Arch Ophthalmol. 2002;120:1463-1469.

11. Cebulla CM, Alegret AM, Feuer WJ, Shi W, Schefler AC, Murray TG. Tumor volume reduction using combined phacoemulsification and intravitreal triamcinolone injection for the management of cataract with treated uveal melanoma and atypical nevi. J Cataract Refract Surg. 2008;34:1669-1673.

12. Haimovici R, Mukai S, Schachat AP, et al. Rhegmatogenous retinal detachment in eyes with uveal melanoma. Retina. 1996;16:488-496.

13. Diener-West M, Reynolds SM, Agugliaro DJ, et al. Development of metastatic disease after enrollment in the COMS trials for treatment of choroidal melanoma: Collaborative Ocular Melanoma Study Group report no 26. Arch Ophthalmol. 2005;123:1639-1643.

14. Newman H, Chin KJ, Finger PT. Subfoveal choroidal melanoma: pretreatment characteristics and response to plaque radiation therapy. Arch Ophthalmol. 2011;129:892-898.

15. Hui JI, Murray TG. Radioactive plaque therapy. Int Ophthalmol Clin. 2006;46:51-68.

16. Collaborative Ocular Melanoma Study Group. Comparison of clinical, echographic, and histopathological measurements from eyes with medium-sized choroidal melanoma in the collaborative ocular melanoma study: COMS report no 21. Arch Ophthalmol. 2003;121:1163-1171.

17. Shah NV, Houston SK, Murray TG, Markoe AM. Evaluation of the surgical learning curve for I-125 episcleral plaque placement for the treatment of posterior uveal melanoma: a two decade review. Clin Ophthalmol. 2012;6:447-452. 
18. Radtke N, Augsburger J, Schmitt T. Management of exudative retinal detachment after plaque therapy for intraocular melanoma. Am J Opthalmol. 1991;112:92-94.

19. Shields CL, Cater J, Shields JA, et al. Combined plaque radiotherapy and transpupillary thermotherapy for choroidal melanoma. Arch Ophthalmol. 2002;120:933-940.
20. Shields CL, Shields JA, Cater J, et al. Plaque radiotherapy for uveal melanoma. Long-term visual outcome in 1106 patients. Arch Ophthalmol. 2000;118:1219-1228.

21. Laqua H, Volcker H. Pars plana vitrectomy in eyes with malignant melanoma. Graefe Arch Exp Clin Ophthalmol. 1983;220:279-284.

\section{Publish your work in this journal}

Clinical Ophthalmology is an international, peer-reviewed journal covering all subspecialties within ophthalmology. Key topics include: Optometry; Visual science; Pharmacology and drug therapy in eye diseases; Basic Sciences; Primary and Secondary eye care; Patient Safety and Quality of Care Improvements. This journal is indexed on

Submit your manuscript here: http://www.dovepress.com/clinical-ophthalmology-journal

\section{Dovepress}

PubMed Central and CAS, and is the official journal of The Society of Clinical Ophthalmology (SCO). The manuscript management system is completely online and includes a very quick and fair peer-review system, which is all easy to use. Visit http://www.dovepress.com/ testimonials.php to read real quotes from published authors. 